\section{Hi . \\ Cystic Fibrosis in India: Past, Present and Future}

\section{Anirban Mandal, Sushil K Kabra* and Rakesh Lodha}

Department of Pediatrics, All India Institute of Medical Sciences, New Delhi, India

\begin{abstract}
Cystic Fibrosis (CF), a genetic, life-limiting, multisystem disease of the Caucasians, does exist in India. Though the exact prevalence is unknown, it is perhaps more common than once thought of. The children with CF in India are diagnosed late, but the clinical features are similar to the patients from rest of the world. Indian patients differ from their counterparts from developed world in being frequently malnourished, having clinical evidence of fat soluble vitamin deficiencies and more chances of being colonized with Pseudomonas. Diagnostic facilities in India are scarce. Mutation profile is different with a lower prevalence of $\triangle \mathrm{F} 508$. Management of $\mathrm{CF}$ in India is difficult due to inadequately trained manpower, lack of financial support, limited availability and high cost of pharmacologic agents. The determinants of early death in Indian children with CF include: severe malnutrition, colonization with Pseudomonas at the time of diagnosis, more than four episodes of lower respiratory infection per year and age of onset of symptoms before 2 months of age. There is need to create awareness amongst pediatricians, develop diagnostic facilities and management protocols based on locally available resources.

Keywords: Airway clearance technique; CFTR mutation; Cystic fibrosis; Delayed diagnosis; Developing countries; India; Malnutrition; Pancreatic enzyme replacement therapy; Sweat test

Introduction

Though not specifically named in the ancient medical literature, there has been awareness about cystic fibrosis as far back as 1857, as popularized by German saying 'the child will soon die whose brow tastes salty when kissed' [1]. On its first description as a distinct clinical entity by Dorothy Andersen in 1938 [2], it was considered as a lethal disease of infancy. Genetic causation and autosomal recessive pattern of inheritance of CF were described in 1946.
\end{abstract}

The 1950s saw the beginning of the sweat test developed as a result of discoveries made by Paul di Sant'Agnese during the heat wave in New York in 1953 [3]. It was later standardized by Gibson and Cooke in 1959 [4]. In 1955, Cystic Fibrosis Foundation was founded and

*Corresponding author: S K Kabra, Department of Pediatrics, All India Institute of Medical Sciences, New Delhi 110029, India, Tel: +91 1126594610; E-mail: skkabra@hotmail.com

Citation: Mandal A, Kabra SK, Lodha R (2015) Cystic Fibrosis in India: Past, Present and Future. J Pulm Med Respir Res 1: 002.

Received: November 17, 2015; Accepted: December 22, 2015; Published: December 31, 2015 chloride transport was identified as the basic physiologic defect of CF in 1983. In 1985 gene causing cystic fibrosis was narrowed down to chromosome 7. This paved the way for Professor Lap-Chi Tsui and colleagues to identify the specific faulty (cystic fibrosis transmembrane conductance regulator) gene in 1989. More recent publication though suggests that it is not CFTR, rather the Proteostasis Network (PN)/and 'Social Network' (SN) and their impact on the CFTR Functional Landscape (CFFL) are the key mechanisms that can explain clinical features and progression of illness [5]. Better understanding of these processes may change the approach to treatment of $\mathrm{CF}$ in future.

Cystic Fibrosis (CF), an autosomal recessive monogenic disorder, is the commonest inherited life limiting illness initially considered to be affecting the Caucasians only. Over past few decades it has been well recognized that $\mathrm{CF}$ exists in all ethnic groups. $\mathrm{CF}$ is a multisystem disorder characterized by involvement of lungs, pancreas and other exocrine glands, manifesting with recurrent respiratory infections, malabsorption and a myriad of complications pertaining to other systems, namely hepatobilliary, endocrine and reproductive. The dominant morbidity remains secondary to pulmonary involvement with commonest cause of mortality being respiratory failure following steady decline in lung function. The role of nutrition on lung function and subsequent outcome in children from India, a developing country with huge burden of under nutrition can never be overemphasized. Ong et al., in their study on Indian children [6] suggested that nutritional differences influence qualitative aspects of lung development in childhood beyond simple isotropic lung growth. They also predicted that lung function must take account of these differences if disease related changes are to be accurately measured.

Over past 5-6 decades with better understanding of pathogenesis of CF, significant improvement has occurred in treatment manifesting as survival benefit. The Cystic Fibrosis Foundation (CFF) has projected a life expectancy of 37 years for CF patients currently [7] and a UK model predicts that a child born with CF today can expect to live past 50 years of age [8]. In countries with limited resources like India, the survival of children with $\mathrm{CF}$ is improving but lags considerably behind the developed countries. Early diagnosis and institution of appropriate treatment is the key to improve survival in children with CF. It is important to create awareness among pediatricians of developing countries. It can be achieved by reviewing information about $\mathrm{CF}$ in individual countries and removing myth that it is disease of Caucasian population alone. Still much has changed in the understanding, identification and management of cystic fibrosis in this country. The main aim of this article is to review details of CF including magnitude of problem, clinical manifestations, how to suspect and diagnose and how to manage suspected children with CF with limitation of resources.

\section{Magnitude of Problem}

The incidence varies considerably among different ethnic groups and country. The birth prevalence is estimated to be approximately 1 in 2500 children born in the United Kingdom [9]. It is less common in African Americans (1 in 15000), Asian Americans (1:31000), American black population $(1: 17,000)$ and the Native American population $(1: 80,000)[10,11]$. 
Cystic fibrosis, once thought to be non-existent in India, was first reported in $1968[12,13]$. Thereafter, there have been reports of CF from all parts of India (Table 1), suggesting that CF occurs in Indian population possibly throughout the geographic or ethnic groups. Literature search suggest a rapid rise of publications related to $\mathrm{CF}$ in India over past two decades. A MEDLINE search using CF and India as search words shows increasing citations with time: for the period 1968-1970: 5 citations, 1971-1980: only two citations, 1981-1990: 5 citations, 1991-2000: 22 citations, 2001-2010: 74 citations and from 2011-2015 (December): 117 citations.

\begin{tabular}{|c|c|c|}
\hline $\begin{array}{l}\text { Author, year of publication } \\
\text { (Ref no) }\end{array}$ & Number of cases & $\begin{array}{c}\text { Diagnostic method } \\
\text { used }\end{array}$ \\
\hline Bhakoo et al., 1968 [12] & 1 & Histopathology \\
\hline Mehta et al., 1968 [13] & 13 & Sweat test \\
\hline Mehta et al., 1969 [14] & 6 & Sweat test \\
\hline Devi et al., 1969 [15] & 4 & Sweat test \\
\hline Gupte et al., 1970 [16] & 6 & Sweat test \\
\hline Reddy et al., 1970 [17] & 12 & Autopsy \\
\hline Venkataraman et al., 1972 [18] & 1 & Autopsy \\
\hline Maya PP et al., 1980 [19] & 3 & Sweat test \\
\hline Jagdish JS 1989 [20] & 1 & Sweat test \\
\hline Prasad ML et al.1990 [21] & 2 & Autopsy \\
\hline Deivanayagam et al., 1990 [22] & 5 & Sweat test \\
\hline Sarkar AK et al., 1992 [23] & 1 & Sweat test \\
\hline Kabra et al., 1996 [24] & 15 & Sweat test, Mutations \\
\hline Kabra et al., 1996 [25] & 13 & Sweat test \\
\hline Kabra et al., 1999 [26] & 62 & Sweat test, Mutations \\
\hline Kabra et al., 2000 [27] & 24 & Sweat test, Mutations \\
\hline Singh M et al., 2002 [28] & 17 & $\begin{array}{c}\text { Sweat test, Mutation, } \\
\text { Autopsy }\end{array}$ \\
\hline Kabra et al., 2003 [29] & 120 & Sweat test, Mutations \\
\hline Ashavaid et al., 2003 [30] & 5 & Sweat test, Mutations \\
\hline Ashavaid et al., 2005 [31] & 39 & Sweat test, Mutations \\
\hline Sharma N et al., 2009 [32] & 50 & $\begin{array}{l}\text { Sweat test, Mutations, } \\
\text { Autopsy, IRT* }\end{array}$ \\
\hline Mir TA et al., 2011 [33] & 3 & Sweat test, Mutations \\
\hline Santra G et al., 2012 [34] & 1 & Sweat test \\
\hline Kawoosa MS et al., 2013 [35] & 18 & Sweat test, Mutations \\
\hline Chakraborty et al., 2014 [36] & 2 & Sweat test \\
\hline Sharma et al., 2015 [37] & 1 & Autopsy \\
\hline
\end{tabular}

There are no community based studies to document precise incidence/prevalence of CF in India. An estimation based on number of CF children registered in CF clinics from Indian subcontinent and total population in defined geographic region has reported 1:12000 from UK and 1:40000 from US [38,39]. A study on 950 cord blood samples investigating carrier state of $\Delta \mathrm{F} 508$ mutation from India calculated incidence of CF as 1:40000 newborns [40]. Available literature suggests that the prevalence of $\mathrm{CF}$ and $\triangle \mathrm{F} 508$ mutation is far more common in northern part of the country compared to South India [29]. Similarly, in Pakistan, $\Delta$ F508 mutation is most frequently reported from the Baluchistan region (South Eastern Pakistan). Baluchistan was hypothesized to be the cradle of this particular mutation from where population migration might have carried the same to India [41].

\section{Estimated Burden of CF in India}

Total estimated live births in India during year 2012 were $27,271,000$ [42]. The number of children born every year with CF may be about 10908 presuming incidence to be about 1 in 2500 live birth; 2727 with a presumed incidence of 1 in 10000; and 681 with a presumed incidence of 1 in 40000. Most of these children may be dying due to severe pneumonia or malnutrition as the diagnosis may not be made due to ignorance or non-availability of diagnostic tests. It is important to create awareness for early identification of children with CF.

\section{Genetics and molecular defect}

The gene responsible for cystic fibrosis, Cystic Fibrosis Transmembrane Conductance Regulator (CFTR) gene, is located on the long arm of chromosome number 7 at position $7 \mathrm{q} 31.2$. The normal allelic variant of this gene is about 250,000 base pairs long with 27 exons. The product of this gene, CFTR protein, is made of 1480 amino acids and is a member of the ATP Binding Cassette (ABC) transporter super family. It functions as a chloride channel, found in membranes of cells that lines passageways of lungs, pancreas, liver, intestines, reproductive tract and skin. The basic defect in cystic fibrosis is mutation of CFTR gene which results in an abnormality of cAMP regulated chloride conductance by epithelial cells on various mucosal surfaces. The failure of chloride conductance leads to dehydration of secretions that are too viscid and difficult to clear [43]. Currently, there are 1997 mutations listed in the CFTR mutation database [44]. CFTR mutations can be grouped into six classes on the basis of their effect on CFTR protein production, trafficking, function or stability. The commonest mutation is $\Delta \mathrm{F} 508$, which constitutes about $70 \%$ of the total cases worldwide [45].

There are only few studies that describe genotypes of Indian children with CF. The frequency of $\Delta$ F508 mutation in Indian children with CF has been reported between 19 to $56 \%$ [46]. Also in other Asian countries, the reported proportion of children with $\Delta \mathrm{F} 508$ is less than that seen in Caucasian population [47]. The spectrum of mutations apart from $\Delta$ F508 in Indian patients is highly heterozygous and some rare and new mutations are also described [27] (Table 2). Detailed analysis suggests that there is variation in mutation profile of children with CF [48]. Children born to parents who had their ancestry from Pakistan had frequency of $\Delta$ F508 almost similar to that of Caucasian population [29]. The heterogeneity in mutation profile is possibly due to variation in ethnic background.

\section{Clinical manifestations}

The presentation of cystic fibrosis is highly variable, ranging from neonates with meconium ileus and severe respiratory compromise, to adults with only mild pulmonary symptoms and no evidence of gastrointestinal disease or even merely with pancreatic dysfunction without any pulmonary manifestations. It has been suggested that $\mathrm{CF}$ is more severe in Asians [38]. Published reports also suggest that clinical profile of Indian children with CF may be different $[25,38,39]$. One major difference is that the diagnosis of CF is delayed in Indian children, which may result in severe malnutrition by the time of diagnosis-one of the bad prognostic indicators for survival [26]. In a study from Chandigarh, the average age at diagnosis was 4.8 years and duration of symptoms was 4.1 years, highlighting delayed diagnosis [28]. The median age of diagnosis among Indian Americans was found to be 12 months compared with 6 months among 


\begin{tabular}{|c|c|c|c|}
\hline Authors [Reference] & Total number of patients & Percentage of patients In whom mutation identified & Mutations identified \\
\hline Kabra et al., [25] & 13 & 61 & $\begin{array}{l}\text { Homozygous } \triangle F 508: 6 \\
\text { Heterozygous } \triangle F 508: 2^{\star}\end{array}$ \\
\hline Kabra et al., [27] & 24 & 75 & $\begin{array}{c}\text { Homozygous } \Delta \mathrm{F} 508: 5 \\
\text { Heterozygous } \Delta \mathrm{F} 508: 4 \\
\text { 3849 + 10 kb C > T:2 } \\
\text { 1 1161delC:1 } \\
\text { 3622insT: } 1 \\
\text { 3123G > C: } 1 \\
\text { 3601-20T > C:2 } \\
\text { R560H:1 } \\
\text { 4569H: } 1\end{array}$ \\
\hline Singh et al., [28] & 17 & 25 (70\% patients tested for mutation) & $\Delta \mathrm{F} 508^{*}$ \\
\hline Kabra et al., [29] & 120 & 22 & $\begin{array}{l}\text { Homozygous } \Delta \mathrm{F} 508: 19 \\
\text { Heterozygous } \Delta \mathrm{F} 508: 7\end{array}$ \\
\hline Ashavaid et al., [30] & $23^{* *}$ & & $\begin{array}{l}\text { Homozygous } \triangle F 508: 4 \\
\text { Heterozygous } \Delta F 508: 1\end{array}$ \\
\hline Ashavaid et al., [31] & 37 & 24 & $\begin{array}{c}\Delta \mathrm{F} 508(24 \%)^{* * *} \\
1525-1 \mathrm{G}>\mathrm{A}\end{array}$ \\
\hline Sharma et el., [32] & 50 & 98 & $\begin{array}{c}\text { Homozygous } \Delta \text { F508:5 } \\
\text { Heterozygous } \Delta F 508: 17 \\
\text { V520F/R117H:1 } \\
\text { I530L/I530L:1 } \\
\text { 876-6del4/876-6del4:1 } \\
\text { 1792ins A/1792ins: } 1 \\
\text { 3986-3987delC/3986-3987delC:1 } \\
\text { 1161 delC:2 } \\
\text { L69H:1 } \\
\text { R117H:1 } \\
\text { Q493L:1 } \\
\text { Y517C:1 } \\
\text { S549N:3 } \\
\text { G551D:1 } \\
\text { E1329Q:1 } \\
\text { N1303K:1 } \\
\text { Y1381H:1 } \\
\text { L218X:1 } \\
\text { R553X:1 } \\
\text { 1525-1G-A:3 } \\
\text { 3120 + 1G-A:2 } \\
3849+10 \mathrm{~kb} \text { C-T:2 }\end{array}$ \\
\hline Shastri et al., [48] & 100 & 41 & $\begin{array}{c}\text { Homozygous } \Delta \mathrm{F} 508 \mathrm{l}: 20 \\
\text { Heterozygous } \Delta \mathrm{F} 508: 13 \\
3849+10 \mathrm{~kb} \mathrm{C}>\mathrm{T}: 2 \\
\text { 1161delC:2 } \\
\text { S549N:2 } \\
\text { 1002-7_1002-5delTTT: } 1 \\
\text { R1158X:1 } \\
\text { G149X:1 } \\
\text { L183l:1 } \\
\text { R352Q:1 } \\
\text { 1002-7_1002-5delTTT+ } \\
\text { 1002-7_1002-5delTTT:1 }\end{array}$ \\
\hline Sachdeva et al., [49] & 225 & 35 & $\begin{array}{c}\text { Homozygous } \Delta F 5081: 45 \\
\text { Heterozygous } \Delta \mathrm{F} 508: 25 \\
\text { p.R1162 } \times 5 / 79 \\
\text { p.M1T } 2 / 79 \\
\text { p.S549N } 2 / 79 \\
\text { p.Cys343 } \\
\text { p.lle1000 } \\
\text { p.M469V } \\
\text { p.l331 } \\
\text { p.R80N11Fs } 11 \\
\text { p.Y808YFs*10 } \\
\text { p.Y577 } \\
\text { p.R75G }\end{array}$ \\
\hline Kawoosa et al., [35] & 18 & $83 \%$ of patients were tested using mutation analysis & $\begin{array}{l}\text { Homozygous } \Delta \mathrm{F} 508 \mathrm{l}: 3 \\
\text { Heterozygous } \Delta \mathrm{F} 508: 2 \\
3849+10 \mathrm{~kb} C>\mathrm{T}\end{array}$ \\
\hline
\end{tabular}

Table 2: Spectrum of mutations in CF patients from India.

*Limited mutation testing; **Include children with clinically suspected CF with normal sweat chloride values in 15 patients; ${ }^{* * *}$ Tested for $\Delta$ F508 and scanning of exons 10 and 11 . 
Caucasian American children, reflecting a low index of suspicion for the disease in Indians, even among Western countries [39]. In the largest case series of cystic fibrosis from India, reported from our center [29], majority of the clinical and laboratory manifestations at presentation were similar to that described in Western series and included recurrent or persistent pneumonia, malabsorption, failure to thrive, rectal prolapse, salt craving, salty taste on kissing, history of dehydration in past, meconium ileus, and skin rashes. The manifestations that were different from western series of CF included: lower CF clinical scores (Schwachman's score), suggesting advanced stage of illness at diagnosis, hypochloremic alkalosis, vitamin A and $\mathrm{D}$ deficiencies, higher colonization rate with Pseudomonas and lower rates of common mutations (Table 3 ).

The high rate of micronutrient deficiencies in Indian children with CF is highlighted in recent studies also [50]. The frequency of colonization by Pseudomonas aeruginosa and antibiotic resistance was higher in Indian children with CF and few were colonized by phenotypically and genotypically distinct strains of the organism [51]. In a recent study from our center [52], CF patients were observed to have high prevalence of peripheral neuropathy. Prevalence of ABPA was also found to be higher in Indian children with CF [53].

In the absence of CFTR expression, fluid secretion into the gut is reduced and the contents get inspissated. In the neonatal period, this manifests as meconium ileus, and later in life, as distal intestinal obstruction syndrome. Few patients of $\mathrm{CF}$, who have residual pancreatic function, can suffer from recurrent attacks of pancreatitis.

CF Related Diabetes (CFRD) affects $2 \%$ of children with CF, while the prevalence increases with age to affect $19 \%$ of adolescents with CF [54]. Counter-regulatory hormones, like glucagon, are also compromised; therefore, ketoacidosis is seldom a complication but hyperosmolar complications and late organ damage may be observed. Corticosteroids accelerate the diabetes which in turn contributes negatively to the prognosis.

CFTR gene mutation and polymorphisms have also been associated with many diseases other than CF. Indian patients with idiopathic chronic pancreatitis were observed to have strong genetic association with CFTR gene mutation [55]. Congenital Bilateral Absence of Vas Deferens (CBAVD) is one of the known manifestations of $\mathrm{CF}$ in men but even non-CBAVD obstructive azoospermia was found to be associated with CFTR gene mutation in India [56].

\section{Diagnosis}

The diagnosis of cystic fibrosis requires a combination of clinical features suggestive of the disease with biochemical or genetic markers of CFTR dysfunction (Table 4) [57].

In a child with a high pretest probability of CF, the diagnosis is confirmed by sweat chloride estimation by pilocarpine iontophoresis method. A sweat chloride concentration of $>60 \mathrm{mmol} / \mathrm{L}$ is almost always diagnostic of CF. As a falsely elevated sweat chloride in the absence of CF is rare, although reported in a number of unusual clinical conditions; they can usually be readily distinguished from CF [58]. Non-classic or atypical CF (1-2\% of CF population), defines patients with a CF phenotype in at least one organ system and a normal or borderline sweat chloride level [59]. In practice, the most common cause of incorrect sweat chloride results is laboratory error; therefore, it is recommended to be done only at CFF accredited care centers [60]. But in countries like India where such facilities are not available, it should be carried out in experienced laboratories and repeated 2-3 times [61].

\begin{tabular}{|c|c|}
\hline Characteristics & Frequency $(N=120)$ \\
\hline \multicolumn{2}{|l|}{ Demography } \\
\hline Mean age at diagnosis & 54 months $(95 \% \mathrm{Cl} 3-154)$ \\
\hline Mean age of onset of symptoms & 11 months $(95 \% \mathrm{Cl} 0.1-60)$ \\
\hline Boys & $80(67 \%)$ \\
\hline Girls & $40(33 \%)$ \\
\hline \multicolumn{2}{|l|}{ Symptoms } \\
\hline Persistent/recurrent pneumonia & $118(98 \%)$ \\
\hline Failure to thrive & $108(90 \%)$ \\
\hline Malabsorption & $96(80 \%)$ \\
\hline Rectal prolapse & $16(13 \%)$ \\
\hline Dehydration & $16(13 \%)$ \\
\hline Meconium ileus & $10(9 \%)$ \\
\hline Vitamin A deficiency & $10(9 \%)$ \\
\hline Salt craving & $5(5 \%)$ \\
\hline Salty taste & $5(5 \%)$ \\
\hline Skin rashes & $5(5 \%)$ \\
\hline Vitamin $D$ deficiency & $4(4 \%)$ \\
\hline Pneumothorax/empyema & $3(3 \%)$ \\
\hline Meconium ileus equivalent & $2(2 \%)$ \\
\hline \multicolumn{2}{|l|}{ Examination } \\
\hline Normal or mild malnutrition & $70(58 \%)$ \\
\hline Severe malnutrition & $50(42 \%)$ \\
\hline Z Scores for weight for age & - 2.59 (95\% Cl: -3.01 to -2.32$)$ \\
\hline Clubbing & $80(75 \%)$ \\
\hline \multicolumn{2}{|l|}{ Chest } \\
\hline Crepitations & $110(92 \%)$ \\
\hline Hyperinflation & $100(83 \%)$ \\
\hline Rhonchi & $40(33 \%)$ \\
\hline Bronchial breathing & $20(17 \%)$ \\
\hline Nasal polyposis & $5(4 \%)$ \\
\hline CF score mean $(95 \% \mathrm{Cl})$ & $51(20-80)$ \\
\hline
\end{tabular}

Table 3: Clinical characteristics of children with cystic fibrosis [29].

\begin{tabular}{|l|}
\hline One or more characteristic clinical features \\
\hline -or a positive newborn screening test result \\
\hline -or a history of CF in a sibling \\
\hline AND \\
\hline $\begin{array}{l}\text { Increased sweat chloride concentration by pilocarpine iontophoresis method on } \\
\text { two or more occasions }\end{array}$ \\
\hline -or identification of two CF causing mutations \\
\hline -or demonstration of abnormal nasal epithelial ion transport \\
\hline Table 4: Diagnostic criteria for cystic fibrosis [57]. \\
\hline
\end{tabular}

As already noted, CF may be diagnosed by identifying two known disease causing mutations. Using a discrete panel of mutations is faster and less costly than expanded mutational analysis. But because of heterogeneity in mutations, a single panel of mutations cannot be used for diagnosis of CF in India. Possibly multiple panel may be required for best diagnostic yield. Till that is available, sweat chloride remains gold standard for diagnosis of CF in India, though it may miss small number of children with normal sweat test having CFTR dysfunction. On the other hand, full sequence analysis will detect 
virtually all CFTR mutations, but its interpretation may be rather difficult as it often uncovers polymorphisms and novel mutations whose significance is not known [57].

With a huge population of around 1.25 billion, there are very few centers in India where sweat chloride test is available. Therefore, the patients have to travel long distances to get the test done and also bear the expenses for the same. So, in many case even if the diagnosis is suspected, it remains unconfirmed [62]. To overcome this problem, we developed and validated an indigenous method for sweat chloride estimation based on pilocarpine iontophoresis and manual titration [63]. The equipment was validated by doing titration of known strength of saline by two observers and by checking inter-observer variation when titration was performed on collected sweat by two independent persons. The mean difference in estimated chloride value from the known strength of saline in 50 samples was $-1.04 \pm 4.13 \mathrm{mEq} / \mathrm{L}$ ( $95 \% \mathrm{CI}:-0.07$ to 2.28 ). The mean difference in the estimated chloride values between two observers when the test was performed on known strengths of saline solution was $-2.5 \pm 4.24 \mathrm{mEq} / \mathrm{L}$ (95\% CI: -3.67 to 1.33 ). The inter-observer variability between two observers when the test was performed on sweat samples obtained from 50 individuals was $-1.12 \pm 4.34$ $\mathrm{mEq} / \mathrm{L}$ (95\% CI: -2.23 to 0.8 ).

Sweat weight of more than $100 \mathrm{mg}$ could be collected in the first attempt in 602 of $757(80 \%)$ patients with an average sweat weight of $230 \mathrm{mg}$. This inexpensive method of sweat collection and chloride estimation has acceptable accuracy and repeatability and can be used in resource poor setting for making a diagnosis of cystic fibrosis [64]. The cost of the equipment is $<10$ US dollar and cost per test is $<1$ US dollar.

If sweat testing facility is not available, then it as advised to look for supportive evidence for CF (Figure 1) and if they are suggestive of CF then refer the patients to a center where sweat testing facility is available.

Nasal Transepithelial Potential Difference (NPD) is a labor intensive and technically difficult method available only at small numbers of CF research centers. It remains to be a research tool and has limited validation as a diagnostic test [57].

Serum Immunoreactive Trypsinogen (IRT) is useful as a screening test in the first few weeks of life but not specific for the disease.

Isolation of Pseudomonas aeruginosa or Burkholdelia cepacia from sputum, cough swabs or BAL is suggestive of CF. Below 20 years of age, cystic fibrosis is the commonest cause of exocrine pancreatic insufficiency [65]. Semi quantitative estimates of fat malabsorption can be made by fecal microscopy or fecal steatocrit [66]. Recently, stool pancreatic elastase-1 has been reported as a sensitive and specific test [67].

Radiological investigations in the form of $\mathrm{x}$-ray and CT scan of chest and sinuses are very non-specific. Chest imaging characteristically reveals bilateral central bronchiectasis, mucous impaction with segmental collapse, air trapping, and there is delayed pneumatization or mucosal thickening in sinuses.

\section{Management}

First and perhaps the most critical part in the management of $\mathrm{CF}$ is to explain the diagnosis to the family. Detailed counseling regarding the nature of the disease, inheritance with risk for recurrence in subsequent pregnancies, and need for regular follow up should be emphasized. The holistic management of a child with cystic fibrosis consists of pancreatic enzyme replacement, supplementation of fat soluble vitamins, salt supplementation, airway clearance, antibiotics and supportive care with help of a multi-disciplinary team consisting of physician, physiotherapist, dietician, microbiologist, psychologist and social scientist [68].

Several obstacles and hindrances are encountered by both patients and healthcare providers in management of cystic fibrosis in a developing country like India. In view of limited resources, it is very difficult to have a team of professionals from different disciplines, necessitating multitasking and heightened dedication from the available members. Availability and cost constraints for various medications (pancreatic enzymes, antibiotics, DNase, etc.) makes management of such patients very difficult. It is desirable that CF patients are followed up regularly every $4-8$ weekly at a center having expertise in the management of CF. But in the Indian scenario, management of CF by individual pediatrician every 4 weeks and visit to centralized service once in 3 months may be an alternative for patients coming from far off places. Early diagnosis, regular follow up, aggressive airway clearance, use of basic microbiology and radiology do not increase cost too much but benefits are significant. Addition of pancreatic enzyme replacement and fat soluble vitamins add to cost with improvement in outcome and can be followed up in majority of patients. Addition of inhaled antibiotics and DNase are useful intervention but increase the costs significantly. Alternatives include the use of low cost treatment in form of hypertonic saline inhalation [69]. The hot and humid climate of Indian subcontinent predisposes these children for chronic dehydration and salt depletion. The scenario is further worsened by episodes of dehydration associated with gastrointestinal diseases and during summer months. The cultural practices that promote over-wrapping of infants and smaller children in Indian communities aggravate such losses. Supplementation of extra salt to these children coupled with parental education is invaluable part of their management.

\section{Future therapies}

Recent advances in the understandings in CF pathophysiology have not yet resulted in dramatic improvements in clinical care, but there is great hope for the future that therapies targeting the basic defect will normalize life of those born with CFTR mutations. Gene therapy attempting to replace the abnormal gene using a viral or liposomal vector is being actively investigated but does not appear to be a therapeutic option for the near future. Disease modifying strategies in $\mathrm{CF}$, other than gene therapy, are approaches that target the protein defect, i.e., CFTR modulators. CFTR modulators can be classified into three classes: potentiators, correctors and read-through agents or premature stop codon suppressors [70]. Ivacaftor, a CFTR potentiator, has been shown to improve CF related functioning and well being [71] and it is currently approved by US-FDA for use in children with $\mathrm{CF}>2$ years of age with 10 selected mutations. It is not effective in homozygous $\Delta$ F508 mutation. Lumacaftor is a CFTR corrector recently being approved for use in combination with Ivacaftor (Orkambi) in patients 12 years and older with homozygous $\Delta$ F508 mutation [72]. Among the read through agents, the most promising current drug Ataluren has shown to improve chloride transport in CF patients with non sense mutation [73].

\section{Prognosis of CF}

Several factors influencing the prognosis in a child with CF can be divided into following three groups, i.e., factors associated with 


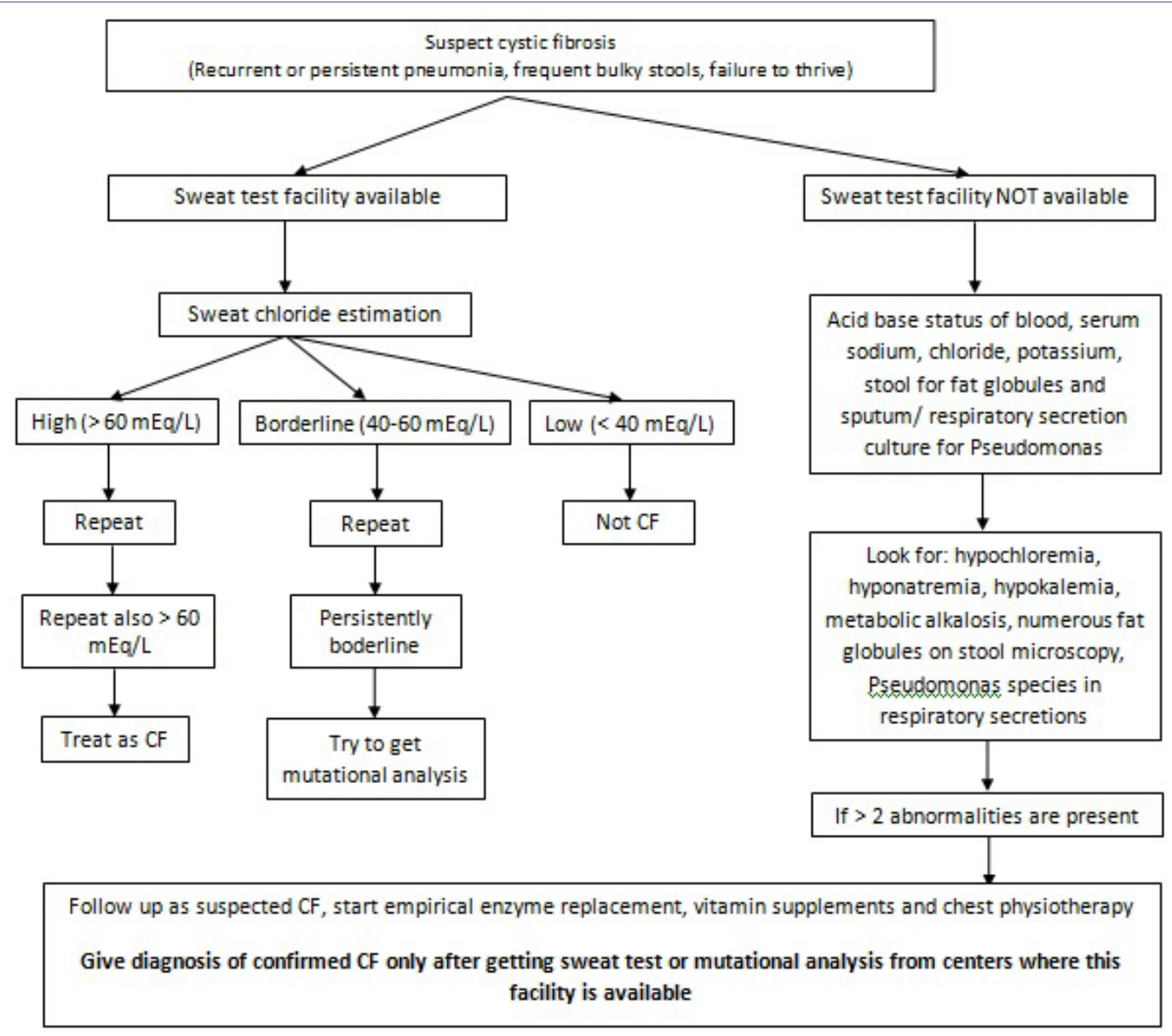

Figure 1: Suggested algorithm for diagnosis and management of cystic fibrosis in resource limited setting.

quality of care, genetics and environment [74]. In Indian perspective, factors related to quality of care stands out with delayed diagnosis and advanced stage of the disease at diagnosis being adversely related to outcome. Absence of newborn screening services precludes early diagnosis and intervention. Lack of CF care centers further complicates the picture by failing to provide adequate care to these children. The most important environmental factor that adversely affects Indian children is socio-economic status. Akin to any other chronic disease, prognosis of CF is also more grave in patients belonging to poor socio-economic status.

Factors that were found associated with decreased survival in our patients include: age at onset of symptoms $<2$ months, frequency of pneumonia $>4$ episodes/year, severe malnutrition at the time of diagnosis and colonization with Pseudomonas at the time of diagnosis [26]. Though we have to go a long way to match with western countries, we feel that early diagnosis, aggressive chest physiotherapy with judicious use of antibiotics and nutritional management can improve the quality of life and survival in CF patients even in developing countries like India.

\section{Research priorities}

- More number of mutation studies in Indian CF patients in an attempt to find out the full spectrum of CF mutation in this country, so that a comprehensive diagnostic panel could be formulated.

- To develop simpler ancillary tests, e.g., aquagenic palmer wrinkling [75] to aid the diagnosis.
- To formulate guidelines for daily salt supplementation in hot and humid climate like India.

- To discover newer and cheaper antibiotics, that can be given through inhaled route achieving higher lung concentrations, especially against resistant pathogens like Pseudomonas.

\section{Summary and Conclusion}

Cystic fibrosis is a multisystem, life limiting, genetic disease recognized throughout the globe amongst all country, race and ethnicities. CF is not rare in India as it was thought to be and should be seriously considered in the differential diagnosis of children with recurrent/persistent respiratory infection and/or chronic malabsorption with failure to thrive. The diagnosis is confirmed by demonstrating elevated sweat chloride levels but genetic confirmation with mutational studies is to be sought wherever possible. In case of non-availability of sweat chloride estimation, ancillary tests are to be carried out and the child should be started on therapy even before giving a diagnostic label. Pancreatic enzyme replacement therapy along with good nutritional support, rigorous airway clearance and antibiotics during pulmonary exacerbations forms the mainstay of management. Since its identification, cystic fibrosis research and care has come a long way to the current state where a person born with the disease can expect a moderately long life with reasonably good quality. The problems pertaining to screening, early identification, prompt diagnosis, appropriate management and adequate follow up in a developing country like India remains a challenge that has to be accepted by the doctors, young researchers and the national health 
system as a whole. There is imminent need to develop diagnostic facilities and medical centers for treatment of CF patients and also to develop model for management of these patients based on locally available resources.

\section{References}

1. Cystic Fibrosis Trust (2015) History of Cystic Fibrosis. Cystic Fibrosis Trust, London, UK.

2. Andersen $\mathrm{DH}$ (1938) Cystic fibrosis of the pancreas and its relation to celiac disease: A clinical and pathologic study. Am J Dis Child. 56: 344-399.

3. Di Sant'agnese P, Darling RC, Perara GA, Shea E (1953) Abnormal electrolyte composition of sweat in cystic fibrosis of the pancreas. AMA Am J Dis Child 86: 618-619.

4. Gibson LE, Cooke RE (1959) A test for concentration of electrolytes in sweat in cystic fibrosis of the pancreas utilizing pilocarpine by iontophoresis. Pediatrics 23: 545-549.

5. Amaral MD, Balch WE (2015) Hallmarks of therapeutic management of the cystic fibrosis functional landscape. J Cyst Fibros 14: 687-699.

6. Ong TJ, Mehta A, Ogston S, Mukhopadhyay S (1998) Prediction of lung function in the inadequately nourished. Arch Dis Child. 79: 18-21.

7. Cystic Fibrosis Foundation (2008) Patient Registry, Annual Data Report 2007. Cystic Fibrosis Foundation, Bethesda, USA.

8. Dodge JA, Lewis PA, Stanton M, Wilsher J (2007) Cystic fibrosis mortality and survival in the UK: 1947-2003. Eur Respir J 29: 522-526.

9. Dodge JA, Morison S, Lewis PA, Coles EC, Geddes D, et al. (1997) Incidence, population, and survival of cystic fibrosis in the UK, 1968-95. UK Cystic Fibrosis Survey Management Committee. Arch Dis Child 77: 493-496.

10. Hamosh A, FitzSimmons SC, Macek M, Knowles MR, Rosenstein BJ, et al. (1998) Comparison of the clinical manifestations of cystic fibrosis in black and white patients. J Pediatrics 132: 255-259.

11. FitzSimmons S (1993) The changing epidemiology of cystic fibrosis. J Pediatr 122: $1-9$.

12. Bhakoo ON, Kumar R, Walia BNS (1968) Mucoviscidosis of lungs. Report of a case. Indian J Pediatr 35: 183-185.

13. Mehta S, Wadhwa UN, Mehta SK, Chhuttani PN (1968) Fibrocystic disease of pancreas in India. Indian Pediatr 5: 185-191.

14. Mehta S, Ansari Z, Wadhwa UN, Walia BN (1969) Fibrocystic disease of pancreas. Indian Pediatr 6: 114-117.

15. Devi CS, Rao NR, Ramaiah Y (1969) Cystic fibrosis of pancreas in adults. A report of 4 cases. Indian J Chest Dis 11: 163-167.

16. Gupte SP, Mehta S (1970) Chronic diarrhoea--an etiological study. Indian Pediatr 7: 625-627.

17. Reddy CR, Sita Devi C, Anees AM, Prasantha Murthy D, Eswar Reddy G (1970) Cystic fibrosis of pancreas in India. J Trop Med Hyg 73: 59-62.

18. Venkataramana G, Kousalya L, Reddy CR (1972) Cystic fibrosis of the pancreas. Indian J Pediatr 39: 337-338.

19. Maya PP, Hill PG, Sudarsanam D, Jadhav M (1980) Cystic fibrosis in South India. Trop Geogr Med 32: 45-49.

20. Jagadish JS (1989) Cystic fibrosis of the lungs. Indian J Pediatr 56: 288-290.

21. Prasad ML, Misra A, Mathur M, Gupta DK (1990) Cystic fibrosis: postmortem report on two cases. Indian Pediatr 27: 493-496.

22. Deivanayagam CN, Venogupalan K, Mallikensan S, Madhavan K, Muthukumaraswamy N (1990) A Clinical profile of cystic fibrosis in South India. Lung India 8: 167-72.

23. Sarkar AK, Bag SK, Biswas SK, Saha SG (1992) Acro-osteolysis of phalanges in a case of cystic fibrosis. Indian J Pediatr 59: 636-639.
24. Kabra SK, Kabra M, Ghosh M, Verma IC (1996) Cystic fibrosis--an Indian perspective on recent advances in diagnosis and management. Indian $\mathrm{J} \mathrm{Pe}$ diatr 63: 189-198.

25. Kabra M, Ghosh M, Kabra SK, Khanna A, Verma IC (1996) Delta F508 molecular mutation in Indian children with cystic fibrosis. Indian J Med Res 104: 355-358.

26. Kabra SK, Kabra M, Ghosh M, Khanna A, Pandey RM (1999) Cystic fibrosis in Indian children: clinical profile of 62 children. Pediatr Pulmonol 19: 337.

27. Kabra M, Kabra SK, Ghosh M, Khanna A, Arora S, et al. (2000) Is the spectrum of mutations in Indian patients with cystic fibrosis different? Am J Med Genet 93: 161-163.

28. Singh M, Prasad R, Kumar L (2002) Cystic fibrosis in North Indian children. Indian J Pediatr 69: 627-629.

29. Kabra SK, Kabra M, Lodha R, Shastri S, Ghosh M, et al. (2003) Clinical profile and frequency of delta 5508 mutation in Indian children with cystic fibrosis. Indian Pediatr 40: 612-619.

30. Ashavaid TF, Dherai AJ, Kondkar AA, Raghavan R, Udani SV, et al. (2003) Molecular diagnosis of cystic fibrosis in Indian patients--a preliminary report. J Assoc Physicians India 51: 345-348.

31. Ashavaid TF, Kondkar AA, Dherai AJ, Raghavan R, Udani SV, et al. (2005) Application of multiplex ARMS and SSCP/HD analysis in molecular diagnosis of cystic fibrosis in Indian patients. Mol Diagn 9: 59-66.

32. Sharma N, Singh M, Kaur G, Thapa BR, Prasad R (2009) Identification and characterization of CFTR gene mutations in Indian CF patients. Ann Hum Genet 73: 26-33.

33. Mir TA, Ashraf M, Ahmed K, Chowdhary J, Rehana B, et al. (2011) Clinical profile, diagnostic delay, and genetic make-up of cystic fibrosis in Kashmir, India. Lung India 28: 97-100.

34. Santra G, Banerjee S (2012) Adult cystic fibrosis--a rare diagnosis from India. J Assoc Physicians India 60: 45-47.

35. Kawoosa MS, Bhat MA, Ali SW, Hafeez I, Shastri S (2014) Clinical and mutation profile of children with cystic fibrosis in Jammu and Kashmir. Indian Pediatr 51: 185-189.

36. Chakraborty PP, Ray S, Bhattacharjee R, Ghosh S, Mukhopadhyay P, et al. (2015) Diabetes and primary infertility in young males: do not forget cystic fibrosis. Clin Diabetes 33: 80-83.

37. Sharma P, Arthi N, Bhattad S, Vaiphei K (2015) Cystic fibrosis in a retro-positive child. Indian J Pathol Microbiol 58: 204-210.

38. Spencer DA, Venkataraman M, Higgins S, Stevenson K, Weller PH (1994) Cystic fibrosis in children from ethnic minorities in the West Midlands. Respir Med 88: 671-675.

39. Powers CA, Potter EM, Wessel HU, Lloyd-Still JD (1996) Cystic fibrosis in Asian Indians. Arch Pediatr Adolesc Med 150: 554-555.

40. Kapoor V, Shastri SS, Kabra M, Kabra SK, Ramachandran V, et al. (2006) Carrier frequency of F508del mutation of cystic fibrosis in Indian population. J Cyst Fibros 5: 43-46.

41. Shah U, Frossard P, Moatter $T$ (2009) Cystic fibrosis: defining a disease under-diagnosed in Pakistan. Trop Med Int Health 14: 542-545.

42. Wikipedia contributors (2015) Demographics of India. Wikipedia, The Free Encyclopedia, San Fransico, USA.

43. Frizzell RA (1995) Functions of the cystic fibrosis transmembrane conductance regulator protein. Am J Respir Crit Care Med 151: 54-58.

44. CFMDB Statistics. Cystic Fibrosis Mutation database.

45. Wilmott RW (1998) Making the diagnosis of cystic fibrosis. J Pediatr 132: 563-565.

46. Ashavaid TF, Raghavan R, Dhairyawan P, Bhawalkar S (2012) Cystic fibrosis in India: a systematic review. J Assoc Physicians India 60: 39-41. 
47. Kabra SK, Kabra M, Lodha R, Shastri S (2007) Cystic fibrosis in India. Pediatr Pulmonol 42: 1087-1094.

48. Shastri SS, Kabra M, Kabra SK, Pandey RM, Menon PS (2008) Characterisation of mutations and genotype-phenotype correlation in cystic fibrosis: experience from India. J Cyst Fibros 7: 110-115.

49. Sachdeva K, Saxena R, Puri R, Bijarnia S, Kohli S, et al. (2012) Mutation analysis of the CFTR gene in 225 children: identification of five novel severe and seven reported severe mutations. Genet Test Mol Biomarkers 16: 798801.

50. Yadav K, Singh M, Angurana SK, Attri SV, Sharma G, et al. (2014) Evaluation of micronutrient profile of North Indian children with cystic fibrosis: a case-control study. Pediatr Res 75: 762-766.

51. Agarwal G, Kapil A, Kabra SK, Das BK, Dwivedi S (2005) Characterization of Pseudomonas aeruginosa isolated from chronically infected children with cystic fibrosis in India. BMC Microbiol 21: 5-43.

52. Chakrabarty B, Kabra SK, Gulati S, Toteja GS, Lodha R, et al. (2013) Peripheral neuropathy in cystic fibrosis: a prevalence study. J Cyst Fibros 12 754-760.

53. Sharma VK, Raj D, Xess I, Lodha R, Kabra SK (2014) Prevalence and risk factors for allergic bronchopulmonary aspergillosis in Indian children with cystic fibrosis. Indian Pediatr 51: 295-297.

54. Moran A, Dunitz J, Nathan B, Saeed A, Holme B, et al. (2009) Cystic fibrosis-related diabetes: current trends in prevalence, incidence, and mortality. Diabetes Care 32: 1626-1631.

55. Midha S, Khajuria R, Shastri S, Kabra M, Garg PK (2010) Idiopathic chronic pancreatitis in India: phenotypic characterisation and strong genetic susceptibility due to SPINK1 and CFTR gene mutations. Gut 59: 800-807.

56. Sharma H, Mavuduru RS, Singh SK, Prasad R (2014) Increased frequency of CFTR gene mutations identified in Indian infertile men with non-CBAVD obstructive azoospermia and spermatogenic failure. Gene 548: 43-47.

57. Farrell PM, Rosenstein BJ, White TB, Accurso FJ, Castellani C, et al. (2008) Guidelines for diagnosis of cystic fibrosis in newborns through older adults: Cystic Fibrosis Foundation consensus report. J pediatr 153: 2-14.

58. Lebecque $P$, Leal T, De Boeck C, Jaspers M, Cuppens $H$, et al. (2002) Mu tations of the cystic fibrosis gene and intermediate sweat chloride levels in children. Am J Respir Crit Care Med 165: 757-761.

59. Rosenstein BJ, Cutting GR (1998) The diagnosis of cystic fibrosis: a consensus statement. Cystic Fibrosis Foundation Consensus Panel. J Pediatr 132: $589-595$

60. LeGrys VA (2001) Assessment of sweat-testing practices for the diagnosis of cystic fibrosis. Arch Pathol Lab Med 125: 1420-1424.
61. LeGrys VA (1996) Sweat testing for the diagnosis of cystic fibrosis: practical considerations. J Pediatr 129: 892-897.

62. Menon P (2012) Cystic fibrosis, are we missing in India? Int J Pharm Sci Rev Res 3: 477-481.

63. Kabra SK, Kabra M, Gera S, Lodha R, Sridevi KN, et al. (2002) An indigenously developed method for sweat collection and estimation of chloride for diagnosis of cystic fibrosis. Indian Pediatr 39: 1039-1043.

64. Schales O, Schales SS (1941) A simple and accurate method for determination of chloride in biological fluids. J Biol Chem 140: 879-884.

65. Stern RC, Boat TF, Doershuk CF (1982) Obstructive azoospermia as a diag nostic criterion for the cystic fibrosis syndrome. Lancet 1: 1401-1404.

66. Littlewood JM, Wolfe SP (2000) Control of malabsorption in cystic fibrosis. Paediatr Drugs 2: 205-222.

67. Daftary A, Acton J, Heubi J, Amin R (2006) Fecal elastase-1: utility in pancreatic function in cystic fibrosis. J Cyst Fibros 5: 71-76.

68. Sinaasappel M, Stern M, Littlewood J, Wolfe S, Steinkamp G, et al. (2002) Nutrition in patients with cystic fibrosis: a European Consensus. J Cyst Fibros 1: $51-75$.

69. Wark P, McDonald VM (2009) Nebulised hypertonic saline for cystic fibrosis Cochrane Database Syst Rev 2: 001506.

70. Derichs N (2013) Targeting a genetic defect: cystic fibrosis transmembrane conductance regulator modulators in cystic fibrosis. Eur Respir Rev 22: 58 65.

71. Quittner A, Suthoff E, Rendas-Baum R, Bayliss MS, Sermet-Gaudelus I, et al. (2015) Effect of ivacaftor treatment in patients with cystic fibrosis and the G551D-CFTR mutation: patient-reported outcomes in the STRIVE randomized, controlled trial. Health Qual Life Outcomes 13: 93-101.

72. Kuk K, Taylor-Cousar JL (2015) Lumacaftor and ivacaftor in the management of patients with cystic fibrosis: current evidence and future prospects. Ther Adv Respir Dis 9: 313-326.

73. Wilschanski M, Miller LL, Shoseyov D, Blau H, Rivlin J, et al. (2011) Chronic ataluren (PTC124) treatment of nonsense mutation cystic fibrosis. Eur Respir J 38: 59-69.

74. Patrick Lebecque (2012) The Prognosis of Cystic Fibrosis - A Clinician's Perspective. In: Sriramulu D (ed.). Cystic Fibrosis-Renewed Hopes Through Research. Intech, Rijeka, Croatia.

75. Gild R, Clay CD, Morey S (2010) Aquagenic wrinkling of the palms in cystic fibrosis and the cystic fibrosis carrier state: a case-control study. $\mathrm{Br} \mathrm{J}$ Dermatol 163: 1082-1084. 